\title{
Synthesis, Characterization and Antibacterial Activity of Ag/PVA Nanocomposite
}

\author{
H. H. Saleh ${ }^{1}$, D. E. El-Hadedy ${ }^{1 *}$, G. A. Meligi ${ }^{2}$, and T. A. Afify ${ }^{1}$ \\ ${ }^{1}$ National Center for Radiation Research and Technology, Atomic Energy Authority (AEA), Egypt \\ ${ }^{2}$ Chemistry Department, Faculty of Science, Ani Shams University, Egypt \\ Received 5 October 2012, accepted in final revised form 24 December 2012
}

\begin{abstract}
Synthesis and characterization of Ag/PVA nanocomposite and comparison of its antibacterial activity with bacteriocin (nisin) for some pathogenic bacteria was carried out. Applications of the bacteriocin include dental care products, pharmaceutical products such as stomach ulcers, colon infection treatment and potential birth control. Ag/PVA nanocomposite was prepared by in situ reduction method, in which silver nitrate, gamma irradiation and poly(vinyl alcohol) (PVA) act as precursor, reductant and stabilizer, respectively. The synthesized $\mathrm{Ag}$ nanoparticles (Ag-Nps) have potential antibacterial activity toward both Gram-positive and Gram-negative bacteria. Further studies by X-ray diffraction (XRD) and transmission electron microscopy (TEM) have demonstrated the structure and the distribution of Ag nanoparticles caped within PVA polymer chain.
\end{abstract}

Keywords: Antibacterial activity; Silver nanocomposite; Poly (vinyl alcohol); Bacteriocin.

(C) 2013 JSR Publications. ISSN: 2070-0237 (Print); 2070-0245 (Online). All rights reserved.

doi: http://dx.doi.org/10.3329/jsr.v5i1.11828 J. Sci. Res. 5 (1), 151-160 (2013)

\section{Introduction}

Nisin is one of the most useful bacteriocins applied in practical applications. They can either be added as preservative (nisin is the only bacteriocin so far to be used in this way) or they can be produced in situ, (i.e., in the product in the case of starter cultures or in the gastrointestinal tract in the case of probiotic strains). Some bacteriocins appeared to be produced as a product [1], but in-vivo production is still an open question. In situ production of antimicrobial substances in the intestine might be enhanced by increasing the adhesion of the probiotic strains to the intestinal mucosa. However, a potential risk with in situ production of bacteriocins in the intestine is that beneficial members of the normal microflora are affected [2]. Nisin is a short peptide antibiotic produced by some strains of Lactococcus lactis subsp lactis. Nisin is nontoxic to humans and is readily

* Corresponding author: dodyelhadedy@yahoo.com 
broken down by digestive enzymes when consumed. Hypersensitivity to nisin has not been recorded so, it has been used as a food preservative in other countries since 1954 and has recently gained approval in the United States for use in certain dairy products [3]. The chemical unit in nisin has a molecular formula $\mathrm{C}_{143} \mathrm{H}_{230} \mathrm{~N}_{12} \mathrm{O}_{37} \mathrm{~S}_{7}$, molecular weight 3354 and normally occurs as a dimer with molecular weight 7000 [4].

Bacteriocin has large antimicrobial activity spectrum against Gram-positive bacteria and their spores, but shows little or no activity against Gram negative bacteria, yeasts or moulds. However, Gram negative bacteria can be sensitized to nisin by exposing to chelating agents (ethylene diamine tetra acetic acid, EDTA), sublethal heat and freezing [5]. Nisin has been accepted as a safe and natural preservative in different areas of food industry and it has also been used in treatment for some health conditions such as stomach and colon ulcers, cosmetic and veterinary products [6].

Recently, the investigation of the attractive antibacterial activities of silver nanoparticles (Ag-NPs) has reclaimed importance due to an increase of bacterial resistance to antibiotics caused by their overuse. Presently, Ag-NPs displaying antibacterial activity are being synthesized. Antibacterial activity of the silver-containing materials can be used, for example, in medicine to reduce infections as well as to prevent bacterial colonization on prostheses, dental materials, vascular grafts, catheters, human skin, and stainless steel materials [7].

Many methods, such as chemical reduction, and radiolytic method have been employed for the synthesis of Ag-NPs [8]. These methods are expected to result in a narrow particle size distribution and particles of uniform shape. Since the metal colloids tend to coagulate, they are usually unstable and difficult to use. As a result, their antibacterial activities are poor. This problem can be greatly overcome by embedding or encapsulating the metal nanoparticles with polymer matrices $[9,10]$. Ag-NPs protected by polymers, such as PVA [11], poly(vinyl pyrrolidone) [12], polystyrene or poly(methyl methacrylate) [13], have been extensively reported. PVA could be considered as a good host material for metal, due to its excellent thermo-stability and chemical resistance [14, 15]. In addition, owing to its water solubility, the Ag-NPs can be easily prepared in aqueous medium and the preparation is virtually non-toxic.

In this work, gamma-radiolytic synthesis of Ag-NPs capped with PVA matrix and a comparative study of the antibacterial activity of Ag/PVA nanocomposites with the bacteriocin (nisin) is reported.

\section{Experimental}

\subsection{Preparation of Ag/PVA nanocomposites}

PVA with a molecular weight of $32000 \mathrm{~g} / \mathrm{mol}$ was obtained from Laboratory Rasayan, Cairo, Egypt and was used as polymeric material. It was in the form of powder, partially hydrolyzed and used without further purification, PVA solution was prepared by 
dissolving $6 \mathrm{~g}$ of PVA in $90 \mathrm{~mL}$ of distilled water. The solution was warmed up to $85^{\circ} \mathrm{C}$ and thoroughly stirred by a magnetic stirrer for $4 \mathrm{~h}$ until the polymer became completely soluble.

For the preparation of $\mathrm{Ag} / \mathrm{PVA}$ nanocomposite films, $10 \mathrm{~mL} \mathrm{AgNO}_{3}$ (obtained from Nice Chemicals Ltd, Cochin, India) solution (0.1M) was added to the prepared PVA solution. The solution stains to cool at room temperature, and after then the solution was casted on a petri dish. The as-prepared Ag/PVA films were irradiated using "Gamma cell 220 Excel ${ }^{60} \mathrm{Co}$ irradiation facility" manufactured by the Atomic Energy Authority of India. The absorbed irradiation dose rate of the $\gamma$-cell was $3.48422 \mathrm{kGy} / \mathrm{h}$. A set of the test Ag/PVA nanocomposite films has received two irradiation doses (25 and $100 \mathrm{kGy}$ ). Finally the irradiated Ag/PVA films were dissolved in deionized water for investigation of the antibacterial activity.

\subsection{Characterization techniques of Ag/PVA nanocomposite films}

Ultraviolet-visible (UV/VIS) double beam Unicam, spectrophotometer (made in England) was used for scanning the absorption spectra. Transmission Electron Microscope (TEM), of the type JEOL JSM-100 CX, Shimadzu Co., Japan was used to study the shape and particle size distribution of the Ag-NPs. X-ray diffraction (XRD) patterns of the samples were performed at room temperature by a (Shimadzu XRD 600) diffractometer, X-ray diffraction patterns were obtained at a scan rate of $2 \% \mathrm{~min}$ on the diffractometer with $\mathrm{CuK}$ radiation, a generator voltage of $40 \mathrm{KV}$, and a generator current of $40 \mathrm{~mA}$ and a wavelength of $0.1546 \mathrm{~nm}$ at room temperature.

\subsection{Cultivation of pathogenic strains (indicator strains)}

Listeria monocytogenes, Escherichia coli, Pseudomonas aeruginosa, Staphylococcus aureus, Micrococcus luteus, Bacillus cereus, Bacillus subtilis, Bacillus polymyxa, Bacillus thurgensis, salmonella $\mathrm{Sp}$ and Streptomyces $\mathrm{Sp}$ were cultured on broth flasks containing L.B. (Lauria Bertani) medium at $37^{\circ} \mathrm{C}$ for $24 \mathrm{~h}$ for the investigation of the antibacterial activity of both Ag-NPs and nisin.

\subsection{Preparation of nisin stock solution}

A stock solution of nisin was purified from Lactococcus lactis $\mathrm{Fc} 2$, isolated and identified by chemical method [16]. It was prepared by dissolving $0.5 \mathrm{~g}$ of nisin either standard or purified by chloroform in a $50 \mathrm{~mL}$ volumetric flask, $0.02 \mathrm{M} \mathrm{HCl}$ was added as a diluent, then the mixture was boiled for $5 \mathrm{~min}$. The stock solution was used to prepare nisin standards contained 0-1000 unit/mg powder using sterile $0.02 \mathrm{M} \mathrm{HCl}$ as a diluent [17]. 


\subsection{The test of indicator strains with nisin and Ag-NPs}

Bacterial susceptibility to antibiotics and bacteriocin can be assessed using the agar diffusion method. In one implementation, $6 \mathrm{~mm}$ paper disks saturated with antibiotic solution at different concentrations were placed on the surface of an agar plate seeded with the test strain. For each of the above mentioned eleven organisms, a set of standard bioassay plates (1.5\% agar, $1 \%$ tween 20, filter paper disks have $6 \mathrm{~mm}$ diameter) LTB (bacterial medium) as assay medium was prepared. From stock solution of nisin $30 \mu \mathrm{L}$ was inoculated on sterilized filter paper discs, compared with different concentrations of antibiotic discs, replicated three times on each set of plates. Following this the plates were incubated at suitable temperature for every indicator strain. The zones of inhibition for both Ag-NPs and nisin were measured.

\section{Results and Discussion}

\subsection{UV/VIS spectroscopic analysis}

The advantage of radiation induced synthesis of Ag-NPs lies in the fact that desired highly reducing radicals can be generated without formation of any byproduct. Fig. 1 shows the optical absorption spectra of pure PVA and Ag/PVA samples. It can be seen that pure PVA sample exhibits a nearly zero absorption in the wavelength range (600-300 $\mathrm{nm}$ ), whereas a strong absorption peak in the wavelength range $(300-200 \mathrm{~nm})$ is obsereved. It is well known that PVA film is transparent and contains only single band; therefore it is expected to absorb radiation only in the far UV region (120-300 nm). The observed absorption band at about $280 \mathrm{~nm}$ may be assigned to $\pi \rightarrow \pi^{*}$ transition. This transition is related to the carbonyl groups $(\mathrm{C}=\mathrm{O})$ associated with ethylene unsaturation $(\mathrm{C}=\mathrm{C})$ of the type $(\mathrm{CH}=\mathrm{CH})_{2} \mathrm{CO}-$. The existence of carbonyl functionalities is probably due to residual acetate groups remain after the manufacture of PVA from hydrolysis of poly(vinyl acetate) or oxidation during manufacturing and processing [18]. One can see a strong absorption peak in the visible regions $(320-500 \mathrm{~nm})$ for irradiated Ag/PVA nanocomposite films relative to unirradiated Ag/PVA sample. Also, the intensity of this absorption peak increases, becomes narrow and sharper as a result of increasing irradiation dose from 25 to $100 \mathrm{kGy}$. This absorption peak is assigned to the plasmon resonance band of radiation-induced Ag-NPs [19]. The surface plasmon band exhibits a blue shift where the maximum of the absorption peak is shifted from $422 \mathrm{~nm}$ to $400 \mathrm{~nm}$ as a result of increasing irradiation dose from 25 to $100 \mathrm{kGy}$. This observation indicates the formation of Ag-NPs within the PVA matrix and also the occurance of quantum size effect as a result of increasing irradiation dose. Also, this indicates that the quantum size effect (i.e. the decreasing of Ag-NPs size) is probably related to the amount of stabilizing PVA polymer chains and also is dependent on irradiation dose. With increasing irradiation dose, the individual PVA macromolecules are assumed to be radiation-induced crosslinked, giving rise to a three dimensional network structure. The crosslinking of 
polymer molecules results in a significant increase in molecular mass, this in turn will increase the amount of polymeer chains surrounding the Ag-NPs [20]. The more radiation-induced polymer chains there are, the more they inhibit either the aggregation and/or the growth of the Ag-NPs. In addition, increasing irradiation dose will increase the nucleation rate which results in the formation of smaller Ag-NPs [20]. These observations can be confirmed from the obtained narrower and sharper surface plasmon peak due to increase in radiation dose from $25 \mathrm{kGy}$ to $100 \mathrm{kGy}$ (Fig. 1).

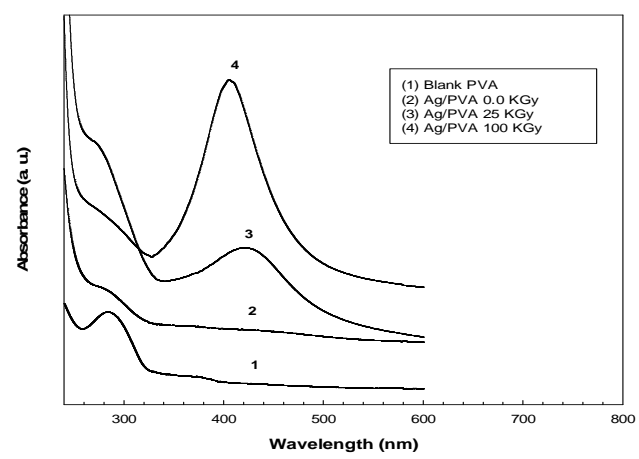

Fig. 1. UV/VIS spectra of pure PVA and irradiated Ag/PVA nanocomposite films

\section{2. $X$ - Ray diffraction (XRD) characterization}

Fig. 2 displays the XRD patterns of pure PVA and irradiated PVA/Ag nanocomposite films. The XRD of pure PVA sample exhibits a strong and broad diffraction peak located at $19.66^{\circ}$. The diffraction peak at $19.66^{\circ}$ corresponds to the (110) reflection, (a plane which contains the extended planar zig-zag chain direction of the crystallites) [21]. A more precise examination and inter comparison of the diffraction patterns for irradiated (25 and $100 \mathrm{kGy)} \mathrm{PVA/Ag} \mathrm{nanocomposite} \mathrm{samples} \mathrm{and} \mathrm{pure} \mathrm{PVA} \mathrm{samples} \mathrm{lead} \mathrm{to} \mathrm{three}$ remarks. First, the as-prepared Ag/PVA nanocomposite shows four new diffraction peaks at $37.8,44.96,64.34$ and $77.8^{\circ}$, respectively. These promoinent peaks can be indexed to the planes (111), (200), (220) and (311), respectively. The indexed diffraction peaks revealed that the Ag-NPs are formed in the PVA matrix with face centered cubic crystal structure. Second, there is a peak broadening as the irradiation dose increases from 25 kGy to $100 \mathrm{kGy}$ for Ag lines in accordance with their small grain sizes. These Ag-NPs have lesser lattice planes compared to bulk, which contributes to the broadening of the peaks in the diffraction pattern. These observation and remarks are considered to be a further confirmation of reduction of $\mathrm{Ag}^{+}$ions to metallic $\mathrm{Ag}$ using either PVA stabilizing polymer and/or irradiation. It can be seen that the preferred growth plane of the Ag-NPs is the (111) lattice plane which shows the highest intensity all over the diffraction pattern. It 
is well known that the average particle size of spherical crystallites can be determined by measuring the full wave at half maximum, (FWHM), of the main diffraction peak. The particle size $(D)$ was calculated based on the regular broadening of XRD peaks as a function of decreasing crystallite size. This broadening is a fundamental property of XRD described by well-established Scherrer Eq. (1):

$$
D=k \lambda / \beta \cos \theta
$$

where, $D$ is the nanoparticle diameter $(\mathrm{nm}), \mathrm{k}$ is the so-called shape factor which usually takes a value of about $0.9, \lambda$ is the X-ray wavelength; $\left(\mathrm{CuK} \alpha=1.540^{\circ} \mathrm{A}\right), \beta$ is FWHM of the peak corresponding to plane (200) and $\theta$ is the diffraction angle corresponding to the maximum intensity peak in XRD pattern $\left(37.8^{\circ}\right)$. The calculated particle size is $4 \mathrm{~nm}$ for $25 \mathrm{kGy}$ irradiated sample and $2 \mathrm{~nm}$ for $100 \mathrm{kGy}$ irradiated one. The obtained XRD pattern (Fig. 2), illustrates that the position and the shape of the reflection peak (111) exhibit a shift to higher angle with increasing irradiation dose. Also, it can be seen that irradiation dose and incorporation of Ag into PVA matrix are determining factors in controlling the particle size of Ag-NPs. This confirms the effect of incorporation Ag-NPs into PVA matrix and irradiation dose on the particle size. Here, it can be concluded that irradiation and the presence of Ag-NPs in PVA matrix decreases the particle size.

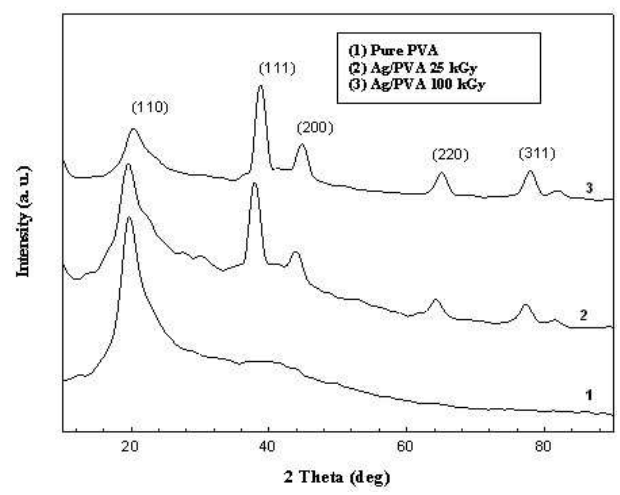

Fig. 2. XRD pattern of pure PVA and irradiated (25 and $100 \mathrm{kGy}$ ) Ag/PVA nanocomposite films.

\subsection{Electron micrographs}

Controlling the size, morphology and distribution of Ag-NPs play an important role on the properties of Ag/PVA nanocomposites. Fig. 3 represents the TEM images of (a) $25 \mathrm{kGy}$ irradiated Ag/PVA and (b) $100 \mathrm{kGy}$ irradiated Ag/PVA nanocomposite samples. A number of well-dispersed Ag-NPs can clearly be seen in the TEM picture of $25 \mathrm{kGy}$ 
irradiated Ag/PVA sample. The Ag-NPs of $25 \mathrm{kGy}$ irradiated sample are well-separated from one another in a large extent and the average diameter of the nanoparticles is $23 \mathrm{~nm}$. On the other hand, the obtained Ag-NPs in the $100 \mathrm{kGy}$ irradiated Ag/PVA nanocomposite sample exhibit a uniform shape and a narrow size distribution with average size of $7 \mathrm{~nm}$. This result means that, the size of the as-prepared Ag-NPs gets smaller and the particle size distribution is improved with the increase of irradiation dose.
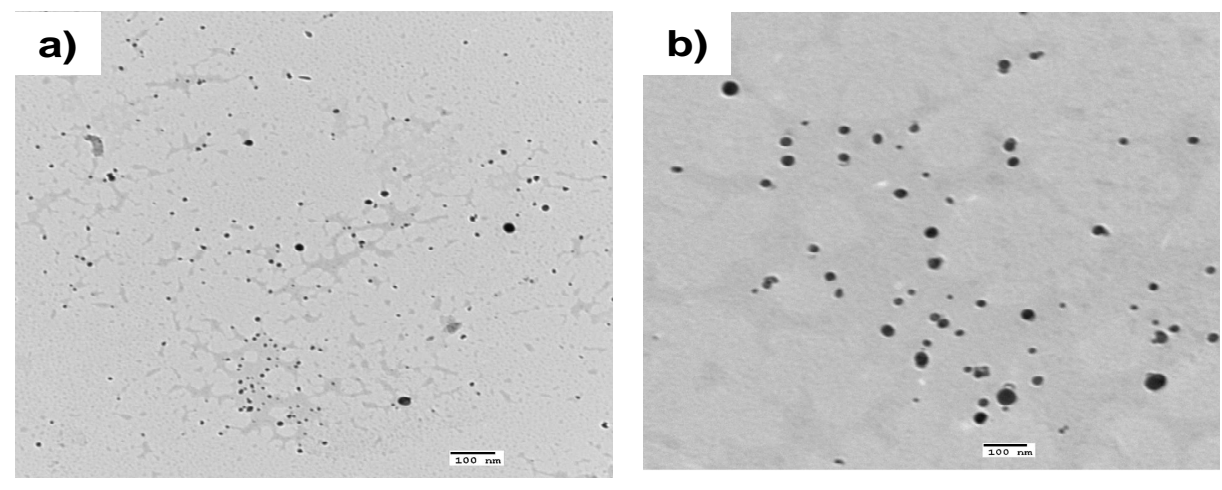

Fig. 3. TEM images of (a) $25 \mathrm{kGy}$ and (b) $100 \mathrm{kGy}$ irradiated Ag/PVA nanocomposite samples.

\subsection{Antibacterial characterization}

\subsubsection{Silver nanoparticles (mode of action)}

The mechanism for the antibacterial action is bacterial membrane disruption by the AgNps released from the Ag/PVA matrix. The Ag-Nps with sulphydryl groups in the cellular wall of the microorganism are responsible for the inhibition halo in the seeded culture media. This result can be explained in terms of the presence of hydroxyl groups in the PVA chain and it is easy to induce Ag-Nps mobility. The Ag-Nps release mechanism is not elucidated. However, it is possible that the hydroxyl group improves the coordination reaction $(\mathrm{Ag}-\mathrm{OH})$ ionic exchange [22]. The antibacterial properties of the Ag-Nps were tested against some gram-positive $S$. aureus and some gram-negative E. coli and the obtained data are presented in Table 1. Antibacterial ability, measured by the diameter of the growth of inhibition zone (disc method), are dependent on the test sample. Ag-Nps are harmful to bacteria [23]. It was found that Ag-NPs react with cell walls and cytoplasmic membranes of Escherichia coli, resulting in pits in the cell wall of bacteria, and finally kill them. The obtained result demonstrated that the irradiated Ag-Nps show greater antibacterial effect than nisin antibiotic, this effect increases with the increase of irradiation dose. This result is in good agreement with the obtained XRD and TEM data, which confirm the decrease of the particle size with the increase of irradiation dose which in turn lead to a good antibacterial activity. 


\subsubsection{Nisin (mode of action)}

The interference of the nisin with membrane function and murein synthesis was studied. The inhibition of the in vivo synthesis of murein in Bacillus subtilis and the resistance of mycoplasma mycoids to nisin, show that the membrane may be excluded as a target. On growth inhibition by nisin with both, cytoplasmic membranes and isolated phospholipid components of membranes were demonstrated. The lysis of phospholipid liposomes by nisin and sensitivity at increased concentration of antibiotic of organisms lacking murein in their cell walls provide further evidence for the cytoplasmic membrane as a target [24].

Table 1. Radius of inhibition zones (RIZ) of control Ag and irradiated Ag-NPs as compared to nisin

\begin{tabular}{|c|c|c|c|}
\hline Indicator strain & Dose, (kGy) & RIZ of Ag-NPs & RIZ of nisin \\
\hline \multirow[t]{3}{*}{ Listeria monocytogenes } & 0.0 & 1.3 & 1.4 \\
\hline & 25 & 1.8 & - \\
\hline & 100 & 2.1 & - \\
\hline \multirow{3}{*}{$\begin{array}{l}\text { Pseudomonas } \\
\text { aeruginosa }\end{array}$} & 0.0 & 2.9 & 2.4 \\
\hline & 25 & 3.1 & - \\
\hline & 100 & 3.4 & - \\
\hline \multirow[t]{3}{*}{ Staphylococcus aureu } & 0.0 & 0.8 & 0.7 \\
\hline & 25 & 1.0 & - \\
\hline & 100 & 1.4 & - \\
\hline \multirow[t]{3}{*}{ Bacillus subtilis } & 0.0 & 2.6 & 2.2 \\
\hline & 25 & 2.8 & - \\
\hline & 100 & 3.0 & - \\
\hline \multirow[t]{3}{*}{ Bacillus cereus } & 0.0 & 2.4 & 1.9 \\
\hline & 25 & 2.5 & - \\
\hline & 100 & 2.7 & - \\
\hline Escherichia & 0.0 & 1.7 & 1.6 \\
\hline \multirow[t]{2}{*}{ Coli } & 25 & 1.9 & - \\
\hline & 100 & 2.2 & - \\
\hline \multirow[t]{3}{*}{ Bacillus thurgensis } & 0.0 & 0.6 & 0.4 \\
\hline & 25 & 0.8 & - \\
\hline & 100 & 0.9 & - \\
\hline \multirow[t]{3}{*}{ salmonella $S p$} & 0.0 & 0.7 & 0.3 \\
\hline & 25 & 0.8 & - \\
\hline & 100 & 1.0 & - \\
\hline \multirow[t]{3}{*}{ Micrococcus luteus } & 0.0 & 2.0 & 1.6 \\
\hline & 25 & 2.7 & - \\
\hline & 100 & 2.9 & - \\
\hline \multirow[t]{3}{*}{ Bacillus polymyxa, } & 0.0 & 2.6 & 2.3 \\
\hline & 25 & 3.0 & - \\
\hline & 100 & 3.2 & - \\
\hline
\end{tabular}


Nisin can inhibit peptidoglycan synthesis at a higher concentration. In cell free systems, nisin caused the accumulation of undecaprenyl-pyrophosphomurein in N (lipid intermediate) [25]. The accumulation was caused by a complex formation between nisin and lipid intermediate according to the following equations [26]:

UDP-MurNAc (pentapeptide) + C55P translocaseC55-PP-MurNAc (pentapeptide) +

UMP

UDP-GlcNAc + C55-PP-MurNAc (pentapeptide) transglycosylase UDP + C 55-PP-

MurNAc (pentapeptide)-GlcNAc

where, MurNAc is N-acetyl muranic acid, GlcNAC is N-acetyl glucose and UPD is uridine diphosphate

In the presence of nisin, reaction (2) is activated, whereas reaction (3) is inhibited. Nisin does not need any receptors, unlike some other antimicrobial peptides, it does need the presence of a membrane potential [27]. The dehydro-amino acids have been suggested to interact with sulfhydryl groups of enzymes. The nisin interferes with the energy supply of the cell. Pores are thought to be created in the cell membrane allowing dissipation of the membrane potential. Cell lysis has been explained by a cationic exchange like process, where, the strongly cationic lantibiotics displace autolytic enzymes [28]. The enzymes weaken the cell wall. The lantibiotics interfere with the cells energy supply, inhibiting the repair of cell wall. The pores formed by the lantibiotics do not allow passage of high molecular weight compounds, resulting in net influx of water, increasing the osmotic pressure and hence causing cell lyses [29].

\section{Conclusion}

In summary, the radiation-induced synthesis of Ag/PVA nanocomposites by a simple and easy route was described in the presence of PVA as a stabilizer. The as-prepared Ag/PVA nanocomposites have a smaller grain size and more narrow grain distribution and besides PVA, irradiation can efficiently protect the nanoparticles from aggregation. The Ag-NPs have a higher antibacterial activity towards both gram-positive and gram-negative bacteria as compared to nisin produced by lactococcus lactis, and the antibacterial activity of AgNPs increased by increasing the irradiation dose.

\section{References}

1. H. Brotz, and HG. Sahl, J Antimicrob. Chemother 46 (1), 1 (2000). http://dx.doi.org/10.1093/jac/46.1.1

2. M. E. Sanders, Adv. Food Nutr. Res. 37, 67 (1993). http://dx.doi.org/10.1016/S1043-4526(08)60116-3

3. J. R. Broadbent, Y. C. Chou, K. Gillies, and J. K. Kondo, J. Dairy Sci. 72 (12), 3342 (1989).

4. B. Jarvis, Biochem. J. 119, 56 (1970) 
5. T. C. V. Penna, A. F. Jozala, T. R. Gentille, J. A. Pessoa, and O. Cholewa, App. Biochem. Biotechnol. 129, 334 (2006). http://dx.doi.org/10.1385/ABAB:129:1:334

6. M. V. Sataszewski, and R. J. Jagus, Int. Dairy, 18(3), 255 (2008), http://dx.doi.org/10.1016/j.idairyj.2007.08.012

7. A. Panacek, L. Kvitek, and R. Prucek, J. Phys. Chem. B. 110, 16248, (2006). http://dx.doi.org/10.1021/jp063826h

8. M. J. Muniz-Miranda, Raman Spectrosc. 35, 839 (2004). http://dx.doi.org/10.1002/jrs.1220

9. Z. H. Mbhele, M. G. Salemane, and J. M. van Sittert, Chem. Mater. 15, 5019 (2003). http://dx.doi.org/10.1021/cm034505a

10. K. S. Chou, and C. Y. Ren, Mater. Chem. Phys. 64, 241, 481 (2000).

11. M. A. A. Omar, E. Saion, M. E. M. Gar-elnabi, E. A. A. Balla, K. M. Dahlan, and Y. M. Yousif, J. Sci. Tech. 12 (1), 104 (2011).

12. P. K. Khanna, R. Gokhale, and V. S. Subbarao, J. Mater. Sci. 39, 773 (2004). http://dx.doi.org/10.1023/B:JMSC.0000030735.08903.a9

13. O. L. A. Monti, J. T. Fourkas, and D. J. Nesbitt, J. Phys. Chem. B 108, 1604 (2004). http://dx.doi.org/10.1021/jp030492c

14. S. Porel, S. Singh, and S. S. Harsha, Chem. Mater. 17, 9 (2005). http://dx.doi.org/10.1021/cm0485963

15. W. H. Eisa, Y. K. Abdel-Moneam, Y. Shaaban, A. A. Abdel-Fattah, M. Amira, Mater. Chem. Phys. 128, 109 (2011). http://dx.doi.org/10.1016/j.matchemphys.2011.02.076

16. H. A. Karem, H. Hussein, S. Badr, and D. El-Hadedy, New Egypt. J. Microbiol. 10 (2005).

17. C. E. Wolf, and W. R. Gibbons, J. Appl. Bacteriol. 80, 453 (1995).

18. R. Jayasekara, I. Harding, I. Bowater, G. B. Y. Christie, and G. T. Lonergan, Polym. Test 23, 17 (2004). http://dx.doi.org/10.1016/S0142-9418(03)00049-7

19. A. M. Whelan, M. E. Brennan, W. J. Blau and J. M. Kelly, J. Nanosci. Nanotech. 4, 66 (2004).

20. I. V Ravindrachary, R. F. Bhajantri, S. D. Praveena, B. Poojary, D. Dutta, and P. K. Pujari, Polym. Degrad. Stab. 95, 1083 (2010). http://dx.doi.org/10.1016/j.polymdegradstab.2010.02.031

21. K. E. Strawhecker., E. Manias, Chem. Mater. 12, 2943 (2000). http://dx.doi.org/10.1021/cm000506g

22. B. Sadeghi, S. Farshid, M. Garmaroudi, H. R Hashemi, A. Nezhad, I. Nasrollahi, A. Sima, and S. Ardalan. Adv. Powder Technol. 3, 25 (2010).

23. K. Chamakura, P. Ballestero, and R. Luo, Colloids Surf. B 84, 88 (2011). http://dx.doi.org/10.1016/j.colsurfb.2010.12.020

24. B. T. Brink, M. Minekus, J. M. B. M. V. Vossen, R. J. Leer, and J. H. J. H. Veld, J. App. Bacteriol. 77,140 (1994). http://dx.doi.org/10.1111/j.1365-2672.1994.tb03057.x

25. W. P. Hammes, M. Renate, and H. Susanne, Int. J. Food. Microbiol. 3, 121 (1986). http://dx.doi.org/10.1016/0168-1605(86)90007-3

26. P. Reisinger, H. Seidel, H. Tschesche, and W.P. Hames, Microbiol. 127, 187. (1980).

27. M. E. C. Bruno, A. Kaiser, and T. J. Montville, Appl. Environ. Microbiol. 58, 2255 (1992).

28. R. W. Jack, J. R. Tagg, and B. Ray, Microbiol. Rev. 59, 171 (1994).

29. P. M. Davidson and D. G. Hoover, Antimicrobial components from Lactic Acid Bacteria. In: Lactic Acid Bacteria, ed. S. Salminen et al. (Marcel Dekker, Inc., New York, 1993) p.127. 